\title{
Poskeynesianos y regulacionistas: ¿Una alternativa a la crisis de la economía estándar?*
}

\begin{abstract}
Robert Boyer**
\section{RESUMEN}

Los dos programas de investigación (el poskeynesiano y el regulacionista) coinciden en el hecho de proponer una alternativa a la economía estándar, cuya incapacidad para dar cuenta de los hechos fundamentales observados -desde la década de los setenta y en particular durante la crisis actual- resulta evidente. Una posible convergencia se manifestó, por un lado, en la formalización del régimen económico de la posguerra -como una forma particular de crecimiento acumulado-, y por el otro en el análisis de los impulsos especulativos que han tenido lugar sucesivamente desde la década de los noventa. La relativa rareza de estas convergencias se explica, en primer lugar, por una referencia más kaleckiana y marxista que keynesiana, en el caso de los regulacionistas. En segundo lugar, por una postura epistemológica diferente: la gran teoría con vocación universal, por un lado, y el análisis situado histórica y espacialmente, por el otro. La profundidad de la crisis que atraviesa la economía estándar, en cuanto a su epistemología implícita, sus conceptos fundadores y sus métodos abre un espacio de colaboración entre poskeynesianos y regulacionistas. El artículo sugiere cuatro caminos para tal cooperación: reconocimiento de la función de las instituciones no sólo en política económica, sino para compensar las fallas del mercado; el análisis sistemático de la pertinencia de las diversas clases de modelos, y no exclusivamente de su coherencia teórica; el enriquecimiento de los mecanismos típicamente keynesianos, con el fin de dar cuenta de la multiplicidad de las interdependencias observadas en las economías contemporáneas; y, finalmente, la asociación con cualquier régimen de crecimiento de largo plazo de los factores que lo pueden desestabilizar, de acuerdo con un proceso de endometabolismo, característico de una economía capitalista. La evolución de las instituciones académicas, nacionales y mundiales, quizá constituya el principal obstáculo para poner en marcha estas investigaciones.

Palabras clave: poskeynesianos, regulacionistas, modelos de crecimiento económico y crisis económica.

Clasificación JEL: E12, E13, E44, G28.

* Fecha de recepción: 19/05/2011. Fecha de aceptación: 01/08/2011. Traducciones del francés de Vania Galindo Juárez.

** Economista, desarrolla sus investigaciones en el Centro de Investigación Económica y sus Aplicaciones (Centre pour la Recherche Économique et ses Applications, CEPREMAP). Es profesor visitante durante el periodo 2010-2011 del Wissenschaftskolleg zu en Berlín. Correo electrónico: robert.boyer@wiko_berlin.de 


\begin{abstract}
Post-Keynesian and régulation research programs have in common to have constructed an alternative to standard economics whose inability to account for the stylized facts observed since the 1970s, and even more in the current crisis, is clear. A first convergence has been about the modeling of the economic post-war growth as a particular form of cumulative causation theory. A second one relates to the analysis of speculative financial booms that have been recurring since the nineties. The relative rarity of these convergences can be explained firstly by the fact that regulation approach is referring more to a Marxist and Kaleckian than typically Keynesian tradition. Secondly, these two research programs rely upon to different epistemological stances: a grand and universal theory one hand, a series of historically and spatially located analyses on the other. The depth of the crisis in mainstream economics implicit epistemology, its founding concepts and methods opens a space for collaboration between post-Keynesians and regulationists. The article suggests four avenues for such a cooperation: recognition of the role of institutions, and not just of economic policy, in offsetting market failures, systematic review of the empirical relevance of the various classes of models and not only of their theoretical coherence, enrichment of typically Keynesian mechanisms in order to reflect the multiple interdependencies found in contemporary economies, and finally association to any long-term growth model of the various factors that may destabilize it, according to a process endometabolism, typical of a capitalist economy. The adverse evolution of academic institutions, both at the national and global level, is perhaps the main obstacle to the implementation of such an intellectually challenging research agenda.
\end{abstract}

Key words: poskeynesian, regulation approach, economic growth models, economic crisis.

Classification JEL: E12, E13, E44, G28. 


\section{INTRODUCCIÓN: UN ORIGEN COMÚN}

A mediados de la década de los setenta la brecha entre las predicciones del paradigma estándar y la evolución macroeconómica de los grandes países de la OCDE se hizo más amplia. Por ello, este momento resulta clave para ambos programas de investigación: el poskeynesiano y el regulacionista. Así, los poskeynesianos pretenden proponer enfoques opcionales tanto al modelo neoclásico de crecimiento como al empobrecimiento del mensaje keynesiano vinculado con la difusión del modelo IS/LM (Harcourt, 1987). Una nueva generación relevará los trabajos de Sidney Weintraub, Paul Davidson, Hyman Minsky, Jan Kregel y también, aunque en menor medida, de Joan Robinson, Nicolas Kalecki y Nicholas Kaldor (Asensio et al., 2011).

Esta fecha también es el punto de partida de otro programa de investigación: el análisis de la regulación y de la crisis del capitalismo estadounidense (Aglietta, 1976) dio origen a una serie de trabajos que se prolongaron hasta los análisis de la gran crisis surgida en 2008 y sobre los cuales esta publicación continúa dando cuenta, siguiendo los pasos de la Revue de la Régulation. Sin lugar a dudas, los fundadores de este enfoque conocen y utilizan los conceptos y las herramientas de los poskeynesianos, pero son inversamente pocos aquellos poskeynesianos que hacen referencia a la contribución, en un sentido complementario, de los regulacionistas.

¿De dónde proviene esta relativa desvinculación? ¿Acaso es inherente a los respectivos fundamentos de estos dos programas de investigación? ¿Acaso la pérdida de legitimidad y la falta de pertinencia de la teoría macroeconómica estándar frente a una crisis que se conoce como venida de fuera no abren una segunda oportunidad de acercamiento con miras a proponer una alternativa? Éste es el hilo conductor del presente artículo.

\section{El SURGIMIENTO DE LOS ENFOQUES de LA REGULACIÓN: MÁS MARXISTA Y APEGADA A LA HISTORIA QUE CARACTERÍSTICAMENTE KEYNESIANA}

Los momentos fundacionales son esenciales, pues es cuando se constituyen preguntas, métodos y prácticas de investigación que perdurarán, más allá de los ajustes y redefiniciones ulteriores. Los enfoques de la regulación, en efecto, siguen marcados por su origen. Los primeros trabajos provienen de macroeconomistas o ingenieros economistas que trabajaban para la administración económica, para 
retomar el término de aquella época, un tanto desvalorizado por el triunfo de la creencia en la superioridad intrínseca de los mercados con respecto a un intervencionismo ilustrado. Así, Michel Aglietta intervino en la construcción de uno de los modelos macroeconómicos utilizados a principios de la década de los setenta por el INSEE, FIFI, mientras que Bernard Billaudot y después Robert Boyer y Jacques Mazier participaron en la elaboración de dos generaciones de modelos en el seno de la Dirección de Previsión del Ministerio de Finanzas (Direction de la Prévision du Ministère des Finances, DECA, STAR).

En el primer caso, la apertura a la competencia internacional convierte la competitividad de la oferta en el factor determinante del crecimiento a mediano plazo, de modo que las políticas keynesianas de gestión de la demanda pierden progresivamente su eficacia. De esta forma, se explica el progresivo pero continuo incremento del desempleo en Francia desde 1967. Así, se introduce el eje rector de las investigaciones ulteriores: ¿cómo se transforman las estructuras del capitalismo y, por tanto, las eventuales regularidades macroeconómicas? El interés de Michel Aglietta se desplaza entonces de la situación de la Francia contemporánea al capitalismo estadounidense; la estanflación y la crisis que se inició en 1973 atestiguan la llegada al límite, en la década de los setenta, de un régimen de acumulación sin precedente: el fordismo.

Una ruptura equivalente de las regularidades incorporadas a los modelos econométricos y de simulación referentes a Francia es el punto de partida de las reflexiones de Bernard Billaudot, Robert Boyer y Jacques Mistral sobre los límites de una teoría macroeconómica ahistórica (Boyer y Mistral, 1978). En estas circunstancias, la crítica se dirige, por supuesto, a la teoría neoclásica de la época y a la ilusión de una teoría del equilibrio general (TEG) como fundamento científico. Sin embargo, el blanco esencial es la teoría marxista, o cuando menos su vulgata, que convierte la ley de la caída de la tasa de ganancia en el alfa y omega del análisis de la dinámica del capitalismo. Ahora bien, las investigaciones sobre los capitalismos, tanto estadounidense (Aglietta, 1976) como francés (Benassy et al., 1978) dan lugar a una transformación en la jerarquía de las formas institucionales. Esta transformación es de tal magnitud que, hasta principios de la década de los setenta, el compromiso salarial fordista y el poderío de una moneda de crédito impulsan un régimen de acumulación sin precedente, en el cual se mantiene una elevada y estable tasa de ganancia, pero a costa de la permanencia de la inflación, incluso en los periodos de recesión.

A partir de entonces, resulta importante dar cuenta de lo anterior a la luz de los modelos de dos secciones productivas, bienes de producción versus bienes 
de consumo, en la tradición de los esquemas de reproducción propuestos por Marx en El capital. Sin embargo, la elección de los parámetros ad hoc se reemplaza por su justificación a partir de las características efectivamente observadas gracias a los datos de contabilidad nacional y a los cuadros input-output relativos a las dos secciones productivas y a la dinámica de los salarios (Bertrand, 1983).

\section{Primera Convergencia: LoS MOdelos de CRECIMIENTo KALDORIANOS}

No obstante, un modelo de este tipo supone una fuerte inversión estadística, de modo que resultaba tentador convertir estos modelos en una formalización que operara en el plan agregado. Dicha formalización permite cotejar los datos macroeconómicos estándar con las teorías alternativas (Boyer, 1988a y 1988b). En este contexto, se produce un encuentro con algunas de las investigaciones poskeynesianas: en efecto, la formalización del régimen de crecimiento fordiano se inscribe, como la especificación de una forma particular de crecimiento acumulativo, en la tradición de los trabajos de Nicholas Kaldor (1985). Cabe destacar que para que un régimen de esta naturaleza exista y sea resistente se deben cumplir ciertas condiciones precisas: existencia de rendimientos crecientes a escala, indexación moderada de los salarios reales a la productividad, poca apertura de la economía a la competencia mundial. A su vez, estas condiciones suponen una configuración particular de las relaciones salariales, de la competencia y de la inserción internacional. Entonces, si las formas institucionales se disponen de manera diferente o evolucionan bajo el efecto del éxito del régimen de acumulación correspondiente, la economía puede converger en otras configuraciones: un crecimiento alimentado por el continuo incremento de la competencia (Petit, 1998) y por el dinamismo de las exportaciones (Boyer y Petit, 1989). De este modo, llegamos a uno de los modelos clave de la influencia kaldoriana, en el cual el peso de la balanza comercial determina el ritmo de crecimiento y limita la posibilidad del pleno empleo (Thirlwall y McCombie, 1994).

\section{Un primer encuentro entre poskeynesianos y regulacionistas}

Éste es el primer encuentro con los poskeynesianos: la contribución de los regulacionistas (figura 1) radica en subrayar el carácter institucionalmente situado de todo modelo macroeconómico, en oposición a una teoría macroeconómica que 
se presentaría como universal y atemporal. Este mensaje tuvo poco eco en el campo de los poskeynesianos, salvo raras excepciones (Setterfield, 2007). Además, los regulacionistas, preocupados por las tendencias de largo plazo, no dejaron de indagar los mecanismos del crecimiento y su modificación tras la extinción y la crisis del fordismo, mientras que los poskeynesianos concentraron sus esfuerzos en las discusiones sobre política económica, es decir, sobre modelos de corto-mediano plazo.

Figura 1. Crecimiento acumulativo y régimen de acumulación fordista

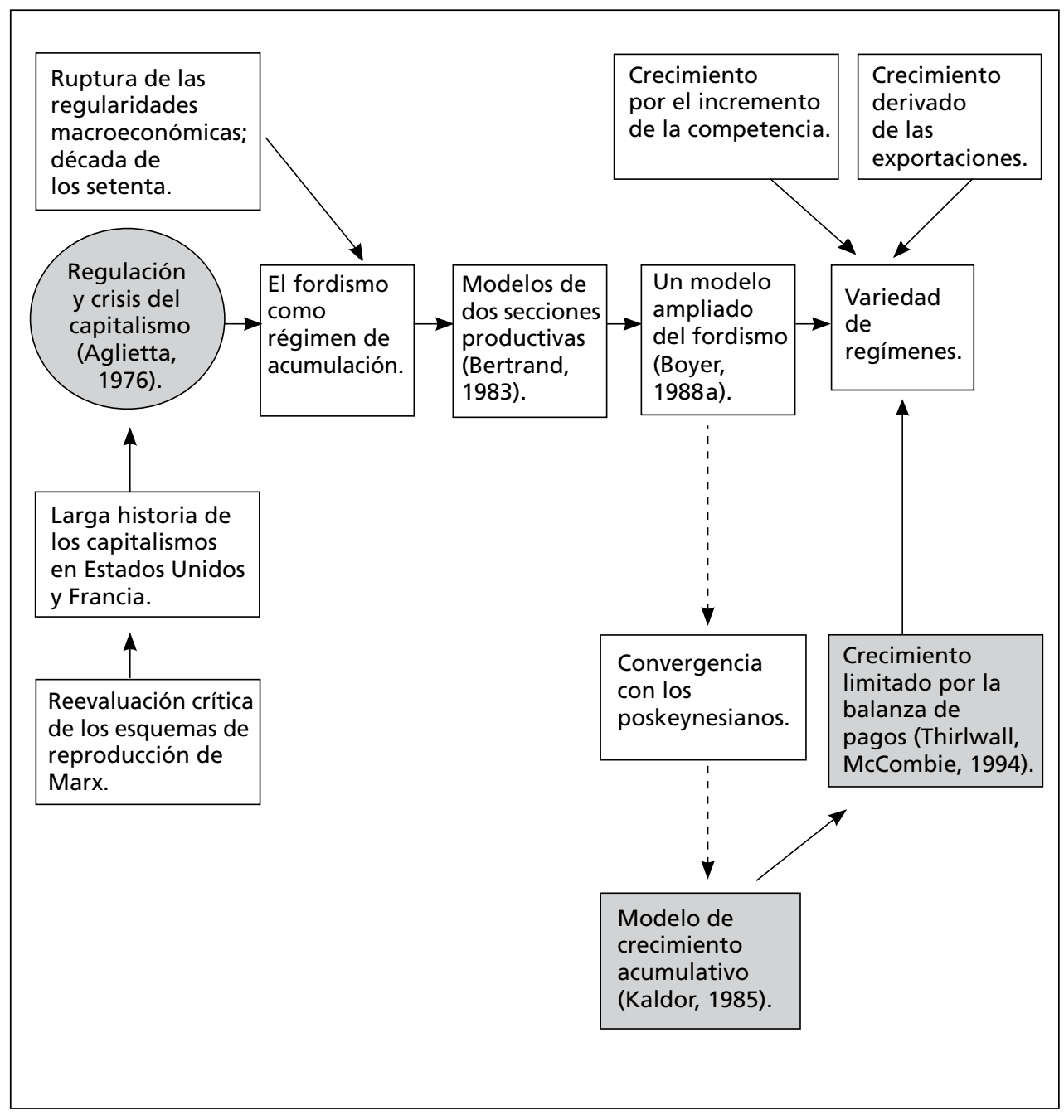




\section{SEGUNDA CONVERGENCIA: LA VIABILIDAD DE UN RÉGIMEN DE CRECIMIENTO DERIVADO DE LAS FINANZAS; EL MODELO MINSKIANO}

Desde la década de los setenta, los regulacionistas intentaron definir con qué nuevo régimen de crecimiento y modo de regulación podría converger la evolución de las formas institucionales. ¿Con el retorno a una regulación competitiva debido a la multiplicidad de estrategias de flexibilización de la relación salarial? ¿Con la dominación del imperativo de competitividad que se encuentra bajo el efecto de la continua reducción de las barreras al comercio internacional? Estas transformaciones sí influyeron pero no al grado de imponer su lógica, ya que a partir de la década de los ochenta la liberalización y la innovación financiera impulsaron una transformación más importante en la gestión de las empresas en nombre del valor accionario, ya fuera el ajuste al empleo, la gestión de la cobertura social -muy particularmente de las jubilaciones- $y$, finalmente, la conducta de la política monetaria. Esta conjunción de cambios estructurales permite mantener tasas de inflación muy bajas, aun cuando la tasa de interés permanece en niveles muy moderados. El fácil acceso al crédito origina, especialmente en Estados Unidos y en el Reino Unido, un nuevo periodo histórico en el que se suceden, primero, la burbuja Internet -gracias al laxo financiamiento de las empresas emergentes basadas en Internet-, y después, cuando dicha burbuja estalla, la burbuja inmobiliaria que surge del relajamiento de las restricciones crediticias, incluso para aquellos estadounidenses cuyo ingreso se estanca y resulta insuficiente para garantizar el reembolso de su crédito hipotecario.

Por consiguiente, los regulacionistas diagnostican, desde finales de la década de los noventa la constitución de un régimen de crecimiento motivado por la financiarización (Aglietta, 1998) que, desde Estados Unidos, difunde sus efectos sobre la cuasi totalidad de las demás economías. En este contexto, vuelve a tener sentido la interrogante de Hyman Minsky: “¿Es posible que sobrevenga una crisis tan grave como la de 1929?". Sus discípulos y los regulacionistas coinciden y dan una respuesta positiva (Boyer, 2000; Aglietta y Rebérioux, 2004). De este modo, al interior de la escuela de las convenciones se impulsaron los análisis de la Teoría general basados en las consecuencias de la incertidumbre acerca del funcionamiento de los mercados financieros: el mercado bursátil, por ejemplo, lejos de converger con un mítico "valor fundamental", utiliza el mecanismo de la alternancia entre las fases al alza y las fases a la baja (Orléan, 1990). A partir del momento en que las finanzas imponen su lógica a las demás formas 
institucionales y se incorporan al comportamiento y a las previsiones de los actores, los impulsos especulativos son los que ponen en marcha la economía. El estallido de la burbuja de las subprimes es entonces más que un ciclo financiero característico, ya que marca el desplome de un sistema financiero en el cual el riesgo radica en la titulización de agentes incapaces de evaluar su naturaleza y amplitud (Boyer, 2011b). Esta crisis financiera sistémica significa también el final de un régimen de crecimiento en el cual el crédito se percibe como la solución a los problemas relacionados con el estancamiento del ingreso medio real y la agudización de las desigualdades.

La hipótesis de la inestabilidad financiera a la Minsky tiene entonces un destacado retorno, pues es una de las pocas problemáticas -junto con los modelos del acelerador financiero que introdujeron sus mecanismos en la economía estándar- que vuelve inteligibles las consecuencias de la liberalización financiera. Por lo tanto, ésta es la segunda convergencia entre poskeynesianos y regulacionistas, al grado de sustentar formalizaciones originales que toman en cuenta el hecho de que son los hogares los que se transformaron en especuladores Ponzi, lo cual introduce una dinámica novedosa con respecto al modelo original, que trataba exclusivamente sobre la estrategia de las empresas (Charpe, 2009). Del mismo modo, cuando se integra la taxonomía de las estrategias financieras (cobertura, especulación, Ponzi), se observa que el crecimiento puede estar ya sea favorecido, ya sea hipotecado, según la distribución de las tres estrategias y el nivel de la tasa de interés fijado por el banco central (Nishi, 2011a). Así, como respuesta a la crisis iniciada en 2008 , emergió un programa de investigación conjunto entre los poskeynesianos y los regulacionistas (véase figura 2).

En este caso, ¿cuál es la aportación de estos últimos? Ésta radica en el uso y la interpretación de dichos modelos. En su permanente querella por la legitimidad, en contraposición con la macroeconomía estándar, los poskeynesianos aseguran que sus modelos son "los buenos", gracias a su superioridad teórica. En contraste, los regulacionistas insisten en la variedad de regímenes cuando cambian los parámetros, que son reflejo del impacto de las formas institucionales particulares sobre las regularidades macroeconómicas. La coherencia teórica es fundamental, pero la pertinencia de las hipótesis no lo es menos: ¿qué interés habría en razonar precisamente acerca de figuras falsas, a sabiendas de que cada intento terminaría en un error? El enfoque de la regulación llama a confrontar, de manera permanente, los datos obtenidos mediante la observación e invita a cambiar algunas hipótesis -ya sean paralelas o técnicas, al interior de una misma teoríaen caso de que el modelo arroje conclusiones sistemáticamente contradictorias con la observación. 
Figura 2. Inestabilidad financiera y acumulación generada por las finanzas

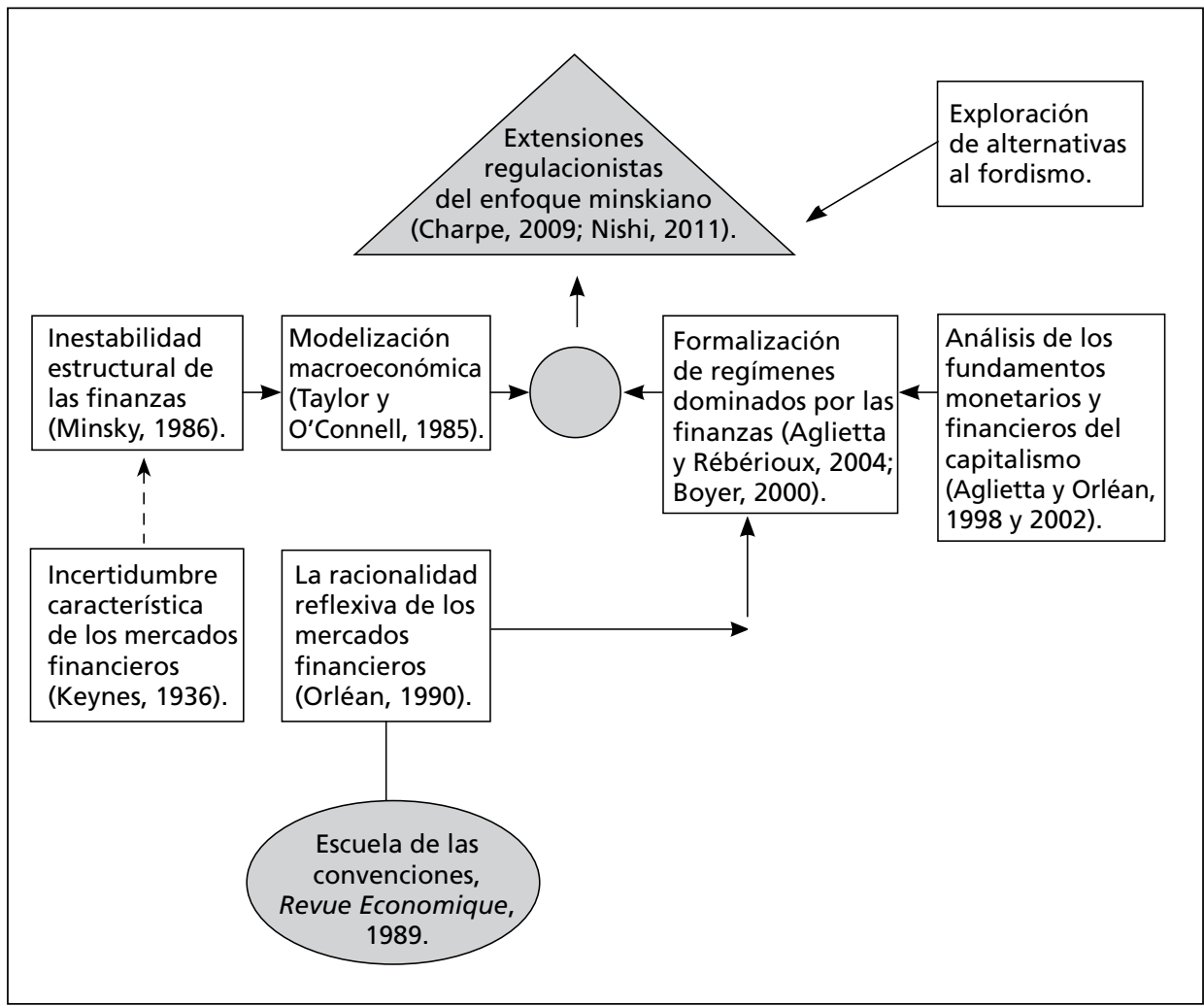

\section{UNA CITA FALLIDA: TIEMPO HISTÓRICO Y DINÁMICA DEL CAPITALISMO EN LA LÍNEA DE JOAN ROBINSON Y MICKAËL KALECKI}

En vista del impacto de la crisis de la década de los setenta sobre el curso de los trabajos poskeynesianos, habríamos podido anticipar que el acento se desplaza de la defensa de la teoría keynesiana stricto sensu hacia un análisis de la dinámica de la acumulación, de sus obstáculos y de la transformación de las instituciones del capitalismo, tanto a escala nacional como internacional. Por un lado, la visión de Mickaël Kalecki de la primacía de la acumulación y la imposibilidad de un pleno empleo duradero debido al poder otorgado a los asalariados se convertía en una visión mucho más pertinente que la del mismo Keynes, muy marcada por las características de la crisis de la economía británica a lo largo de la 
década de los años treinta. Esto es lo que Joan Robinson destaca en el artículo que le dedica en 1974. Por otro lado, de manera más general, la misma autora opone los enfoques en términos de equilibrio, característicos de la teoría neoclásica, a la comprensión de los procesos históricos: "En cuanto admitimos que la incertidumbre de las previsiones es la que guía los comportamientos económicos, el equilibrio pierde su pertinencia y la historia ocupa su lugar" (Robinson, 1974, p. 1). Esta crítica se dirige a la teoría walrasiana... lo cual no le impedirá, dos décadas más tarde, invadir la macroeconomía con los modelos del ciclo real de negocios (RBC, por sus siglas en inglés) y luego, con los modelos de equilibrio general dinámicos y estocásticos (DSGE, por sus siglas en inglés)... ¡hasta volver imposible y por tanto incomprensible la crisis de las subprimes!

Desafortunadamente son pocos los poskeynesianos que tomaron en serio la inclusión de la historia en la teoría macroeconómica. Ciertamente, la controversia sobre la medición del capital demostró que las funciones de producción estimadas con base en datos históricos, lejos de provenir de limitaciones tecnológicas, no hacían más que expresar las interacciones entre acumulación, cambio técnico y crecimiento. Sin embargo, habría sido fundamental reflexionar sobre los cambios institucionales posteriores a la segunda Guerra Mundial, que alejan a las economías británica y estadounidense de la configuración de la entreguerra: uso pleno de la moneda de crédito, institucionalización de los derechos de los asalariados y el inicio de una fuerte socialización de la inversión y la circunscripción de las finanzas en el nivel nacional e internacional. No obstante, en el seno mismo de la problemática de la Teoría general, estas instituciones y formas de organización van a desempeñar una función determinante en la disminución de la incertidumbre a la que se enfrentan tanto empresarios como inversionistas. A pesar de que los agentes, abandonados a su suerte, van a generar expectativas que conduzcan a una inestabilidad intrínseca de los mercados financieros, la mediación entre instituciones y políticas puede ayudar a canalizar estas fuerzas desestabilizadoras (Shackle, 1974). Éste es el fundamento de la renovación de las teorías institucionalistas modernas (Escuela de las Convenciones, 1989; North, 1990; Aoki, 2002): convenciones, organizaciones e instituciones canalizan las expectativas y participan en la coordinación económica en la misma medida que los mercados cuyas fallas pueden contrarrestar. En retrospectiva, es una lástima que los poskeynesianos no hayan echado mano de esta dialéctica entre incertidumbre e instituciones, ya que probablemente así habrían podido cortar de raíz la contrarrevolución de las previsiones racionales. Al argumentar, con justa razón, que si las políticas económicas y las reglas del juego cambian 
los agentes económicos adaptan su comportamiento, Robert Lucas (1983) en realidad estaba reintroduciendo una macroeconomía prekeynesiana, basada en el uso abusivo de la teoría walrasiana, puesto que se construyó sobre una economía de un solo agente representativo que optimiza su comportamiento en un horizonte intertemporal.

Sin embargo, en sus últimos trabajos, Joan Robinson también subrayó otra historicidad de las economías capitalistas: en cuanto los teóricos terminaron de entender los mecanismos y condiciones de un régimen de crecimiento, este último entró en crisis y los obligó a poner nuevamente en marcha sus esfuerzos para comprender las economías contemporáneas. No se trata más que del eje rector de las investigaciones regulacionistas: no existe un régimen de acumulación dotado de estabilidad estructural a largo plazo, pues las crisis, de gravedad desigual, son la expresión misma de la lógica de este modo de producción: el capitalismo. Así, no sólo podemos concebir y observar diversos regímenes de este tipo en un momento dado, sino que además cada uno de ellos es portador de crisis cíclicas y, sobre todo, de grandes crisis específicas.

Numerosos poskeynesianos se ven tentados a considerar que la posibilidad de formalizar estos procesos históricos está fuera de todo alcance. Algunos regulacionistas fueron más audaces y propusieron formalizaciones que explicaban, dentro del mismo marco analítico y sin hacer referencia a un choque exógeno en particular, las fluctuaciones regulares a lo largo de una trayectoria de crecimiento y, luego, una violenta sacudida de la economía que la llevaría a cambiar el curso de su trayectoria (Lordon, 1997b). Esta discontinuidad es acorde con las observaciones históricas de las grandes crisis: la crisis de 1929, la que empezó en 1973 y luego la gran sorpresa que resultó -para los partidarios de la macroeconomía estándar- el colapso del sistema financiero estadounidense en septiembre de 2008. No obstante, una parte del gremio sigue argumentando una serie de perturbaciones venidas de afuera: un brutal afán de lucro y pérdida de moralidad en Wall Street, una caída de la productividad en el mercado inmobiliario y una ola de irracionalidades por parte de los prestamistas. La primacía de la hipótesis de la eficiencia de los mercados y de su estabilidad intrínseca condujo a la macroeconomía contemporánea a un impasse.

Ésta es la circunstancia ideal para una conjunción de las investigaciones poskeynesianas y regulacionistas en torno de la construcción de modelos que formalicen estos procesos endógenos de desestabilización de una configuración institucional (figura 3). En efecto, se puede observar la inclusión de los cambios estructurales en algunos trabajos poskeynesianos, pero ésta se asocia con la 
búsqueda de senderos de crecimiento estables a largo plazo que garanticen el pleno empleo (Pasinetti, 1981). Ahora bien, Kalecki y Goodwin coinciden en que esto contradice la lógica y los motivos que implica un régimen capitalista. Por consiguiente, resulta factible hacer una hibridación de estos dos programas de investigación. Su atractivo debería reforzarse con las enseñanzas de la crisis iniciada en 2008 (Setterfield, 2011):

- En los capitalismos dominados por las finanzas, un crecimiento fuerte y estable seguido de un brutal colapso, antes de que demostraran ser necesarias las intervenciones públicas masivas.

- Una incertidumbre radical en cuanto a las reformas que permiten reducir un desempleo que se ha vuelto estructural.

- Una fuerte diferenciación de las trayectorias nacionales.

Entonces, las teorías deben tomar en cuenta la irreversibilidad y la no ergodicidad de los sistemas económicos, y los poskeynesianos forman parte activa de esta reevaluación (Asensio y Lang, 2010).

\section{Una cita pendiente, pero un campo de investigación futuro}

Figura 3. El endometabolismo de los regulacionistas como prolongación de la historicidad de los regímenes de crecimiento de Joan Robinson.

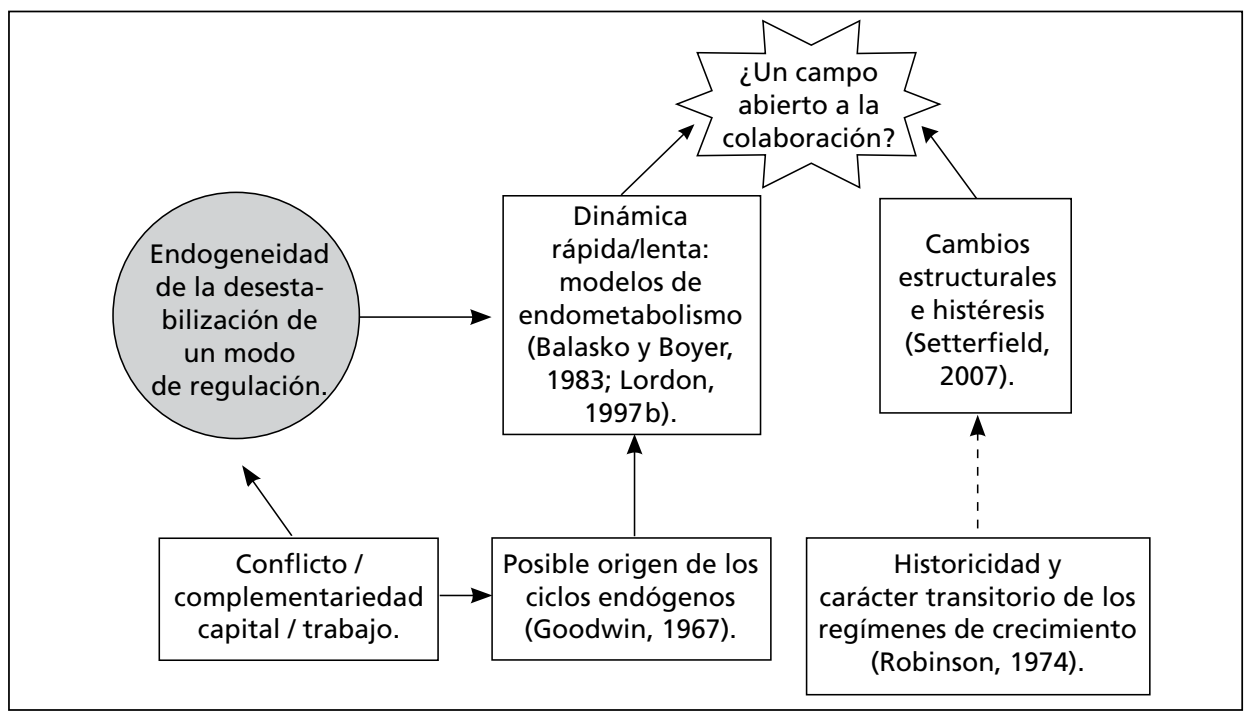




\section{DIFERENCIAS DE ENFOQUE: ¿INCOMPATIBILIDAD O POSIBLE COMPLEMENTARIEDAD?}

A la luz de esta breve retrospectiva, ¿cómo explicar el reducido número de encuentros entre poskeynesianos y regulacionistas, siendo que comparten un mismo objetivo: construir un marco analítico que dé cuenta de las evoluciones observadas desde la década de los setenta, es decir, la gran cantidad de anomalías de la economía estándar que se alejó de la revolución keynesiana? El resultado se contrasta en el cuadro 1.

Cuadro 1. ¿Cuál es el grado de compatibilidad entre los dos programas de investigación?

\begin{tabular}{|c|c|c|}
\hline$\overbrace{\text { CARACTERÍSTICAS }}^{\text {PROGRAN }}$ & POSKEYNESIANOS & REGULACIONISTAS \\
\hline \multicolumn{3}{|l|}{ 1. Epistemología } \\
\hline Implícita/explícita & $\begin{array}{l}\text { De un enfoque implícito a la } \\
\text { Kuhn (el paradigma keynesiano } \\
\text { es una alternativa a la teoría } \\
\text { estándar) a un realismo crítico a } \\
\text { la Lawson. }\end{array}$ & $\begin{array}{l}\text { De cierto tipo de positivismo } \\
\text { a un enfoque constructivista } \\
\text { (Palombarini). }\end{array}$ \\
\hline \multicolumn{3}{|l|}{ 2. Metodología } \\
\hline - Modelización & $\begin{array}{l}\text { - Principalmente con miras } \\
\text { teóricas. }\end{array}$ & - Teórica y práctica a la vez \\
\hline $\begin{array}{l}\text { - Naturaleza de la } \\
\text { prueba. }\end{array}$ & $\begin{array}{l}\text { - Conformidad con los hechos } \\
\text { estilizados y la calibración. }\end{array}$ & $\begin{array}{l}\text { - Pertinencia de las hipótesis, } \\
\text { conformidad con los hechos } \\
\text { fundamentales, pruebas } \\
\text { econométricas. }\end{array}$ \\
\hline $\begin{array}{l}\text { - Relación con las } \\
\text { demás ciencias } \\
\text { sociales. }\end{array}$ & - Poca relación explícita & $\begin{array}{l}\text { - Imbricación de la } \\
\text { economía en las ciencias } \\
\text { sociales (historia, política, } \\
\text { sociología). }\end{array}$ \\
\hline \multicolumn{3}{|c|}{ 3. Concepción del tiempo } \\
\hline & $\begin{array}{l}\text { - Más bien cinemático o } \\
\text { histórico débil, incluso si } \\
\text { hay histéresis. }\end{array}$ & $\begin{array}{l}\text { - Superposición de diversas } \\
\text { escalas de tiempo } \\
\text { (económico e institucional). } \\
\text { Fuerte historicidad de los } \\
\text { regímenes económicos. }\end{array}$ \\
\hline \multicolumn{3}{|c|}{ 4. Concepción de la política económica } \\
\hline - Visión & $\begin{array}{l}\text { - Esencial para la } \\
\text { estabilización } \\
\text { macroeconómica. }\end{array}$ & $\begin{array}{l}\text { - El complemento para una } \\
\text { arquitectura institucional, } \\
\text { no su fundamento. }\end{array}$ \\
\hline
\end{tabular}




\begin{tabular}{|c|c|c|}
\hline CARACTERÍSTICAS & POSKEYNESIANOS & REGULACIONISTAS \\
\hline \multicolumn{3}{|c|}{ 4. Concepción de la política económica } \\
\hline $\begin{array}{l}\text { - ¿Acción sobre la } \\
\text { demanda? }\end{array}$ & $\begin{array}{l}\text { - Necesaria, ya que la } \\
\text { demanda efectiva se aparta } \\
\text { de la demanda del pleno } \\
\text { empleo. }\end{array}$ & $\begin{array}{l}\text { - Parte integrante de un } \\
\text { régimen de acumulación. }\end{array}$ \\
\hline $\begin{array}{l}\text { - Elección entre } \\
\text { presupuesto y } \\
\text { moneda. }\end{array}$ & $\begin{array}{l}\text { - Al momento de las } \\
\text { depresiones, trampa para } \\
\text { la liquidez; por lo tanto, } \\
\text { necesidad de una acción vía } \\
\text { el presupuesto. }\end{array}$ & $\begin{array}{l}\text { - Su eficacia relativa } \\
\text { varía según el modo de } \\
\text { regulación. }\end{array}$ \\
\hline $\begin{array}{l}\text { - Papel de las } \\
\text { reformas } \\
\text { institucionales. }\end{array}$ & $\begin{array}{l}\text { - Se menciona poco, salvo en } \\
\text { el sistema internacional. }\end{array}$ & $\begin{array}{l}\text { - Determinante en las } \\
\text { grandes crisis para reajustar } \\
\text { la compatibilidad de las } \\
\text { formas institucionales. }\end{array}$ \\
\hline $\begin{array}{l}\text { - Relación con el } \\
\text { poder político. }\end{array}$ & $\begin{array}{l}\text { - Convencer a los políticos } \\
\text { del acierto de la teoría } \\
\text { poskeynesiana y, por lo } \\
\text { tanto, de las medidas que } \\
\text { ésta propone. }\end{array}$ & $\begin{array}{l}\text { - Comprender los procesos } \\
\text { sociales que dan forma a } \\
\text { las políticas económicas. }\end{array}$ \\
\hline
\end{tabular}

\section{Postulados epistemológicos: Una convergencia notoria}

El tema es decisivo, ya que los vicios de los modelos tipo RBC y DSGE pusieron de manifiesto la fragilidad epistemológica de esta corriente que utiliza y abusa de la facilidad del "como si" para imponer un modelo normativo exento de toda refutación. En efecto, calibrar los parámetros y reducir la dinámica económica a choques exógenos lo liberan del criterio popperiano de falsabilidad (o refutabilidad) que, al término de la segunda Guerra Mundial convertía, teóricamente, el análisis económico en la ciencia social más avanzada.

La primera generación de autores poskeynesianos le produce al observador externo la impresión de que para ellos la publicación de la Teoría general es el momento de la ruptura epistemológica. Ahora bien, este texto dista de presentar un paradigma único, tal como lo demuestra la diversidad de modelos que se derivaron de él: la reintegración en la síntesis del esquema IS/LM, la economía del desequilibrio de Clower a Benassy, la irreductibilidad de la incertidumbre a la Schakle, el modelo de la inestabilidad financiera posterior a Minsky, la teoría de la economía monetaria de producción, sin dejar de lado su prolongación en materia del crecimiento (Harrod, Domar y Kaldor), así como una posible convergencia con Kalecki y el acento en la dinámica de la acumulación impulsado por 
Joan Robinson. En consecuencia, los sucesores de Keynes no pudieron oponer el equivalente de los modelos RBC y DSGE a la invasión de la macroeconomía por parte de la teoría walrasiana, sobre todo porque esos modelos se presentaban como una "generalización" del modelo IS/LM. Según otra interpretación, estos modelos pertenecen más bien al mismo paradigma en el sentido de Thomas Kuhn (1962), pero los keynesianos no supieron, o no pudieron convencer a los políticos, quienes por lo contrario sucumbieron primero al encanto del monetarismo y luego al de la nueva teoría clásica. La tarea consistiría entonces en reafirmar la pertinencia del enfoque keynesiano. Esta tesis recupera vigor después de septiembre de 2008: ¿acaso no todos los gobiernos volvieron a ser keynesianos, en el sentido de que reconocen la necesidad de una herramienta presupuestaria -0 cuando menos de los estabilizadores automáticos- para contener los riesgos de depresión?

De hecho, la segunda generación de poskeynesianos parece haber relativizado la concepción de Kuhn; tanta fue la influencia del cinturón protector de las hipótesis adjuntas para incitar a la mayoría de los macroeconomistas a conservar el paradigma walrasiano, enmendado únicamente por las hipótesis ad hoc: como siempre, la rigidez de los salarios, un comportamiento un tanto irracional de los consumidores y también cada vez más por parte de las finanzas, sin renunciar a la hipótesis de la eficiencia (Boyer, 2010). En este contexto, el realismo crítico provee una representación más exacta del trabajo de los economistas (Lawson, 2003). Realismo porque algunas propiedades económicas existen, independientemente de la forma en que trata de explicarlas el análisis. Crítico porque pertenece al debate de buscar cuáles de sus características son pertinentes para una época y para una sociedad determinada. Los poskeynesianos, al menos algunos de ellos, parecen abandonar la pretensión de un conocimiento irrefutable de las propiedades intrínsecas de un modelo económico (Asensio y Lang, 2010).

Ahora bien, la nueva generación de regulacionistas confluye hacia una concepción análoga en materia de epistemología económica, a partir de una posición inicial marcada por un tipo de positivismo. En efecto, el acento de los primeros trabajos sobre las pruebas econométricas que muestran la alta probabilidad de ruptura del régimen de crecimiento fordista incitaba a cierto optimismo en cuanto a la posibilidad de elaborar una teoría más respetuosa de la información obtenida de la observación. No sólo las pruebas estadísticas debían ser utilizadas para delimitar el grado de viabilidad del concepto de fordismo, sino que podían ser utilizadas para refutar la macroeconomía dominante de la época, y más aún las pretensiones de la teoría walrasiana de sustituir a la de Keynes. 
Tres décadas más tarde, es necesario reconocer que la nueva ortodoxia resistió la gran cantidad de "anomalías" que aparecieron al momento de su aplicación: parámetros inverosímiles provenientes de la calibración de los modelos, falsa exogeneidad de los choques de productividad que dan origen a los ciclos, errores sistemáticos entre las predicciones de estos modelos y las observaciones que culminan con la incapacidad de anticipar la crisis iniciada en 2008.

Este aggiornamento en materia epistemológica tuvo lugar, sobre todo, cuando el programa de investigación regulacionista se preocupó por introducir lo político en el marco conceptual inicial. Un enfoque normativo -basado en la cientificidad de los modos de regulación alternativos que entró en crisis en la década de los setenta- apareció rápidamente, desprovisto de sentido, puesto que no hacía sino repetir, agravándola, la ilusión de los keynesianos en cuanto a su necesaria victoria en materia de política económica, ¡dada la superioridad de su paradigma! Parecía mucho más realista y productivo subrayar "el carácter construido de la comprensión científica, la inconmensurabilidad de las lógicas que sostienen el discurso teórico y el discurso político (...). La comprensión de lo existente, es decir, su formalización racional, es el fin último de la actividad científica (...). Esto supone una fractura definitiva entre el momento de la comprensión teórica de lo real (posible solamente ex post) y el momento de la acción política" (Palombarini, 1999, p. 97).

Por consiguiente, este punto de encuentro es una buena noticia en lo referente a la posibilidad de construir colaboraciones, pero entonces se presentan otras dificultades en un nivel distinto.

\section{2. ¿Dar cuenta de los procesos históricos o buscar una nueva Teoría general?}

En materia de estrategias de investigación, parece que los poskeynesianos se enfocan mucho en la construcción teórica, cuya coherencia y poder deberían esclarecer de manera pertinente los problemas macroeconómicos contemporáneos. Desde hace dos décadas, la estrategia de los regulacionistas ha consistido en acumular estudios históricos de larga duración y comparaciones internacionales, con el fin de ampliar la gama de regímenes económicos, mucho más allá de la oposición entre regulación competitiva/regulación administrada, o entre acumulación extensiva e intensiva. Los conceptos básicos se revisan a la luz de estos resultados, se introducen nuevamente, y la lista de los factores y mecanismos que contribuyen a la coherencia de una forma de desarrollo no cesa de alargarse y la taxonomía de las arquitecturas institucionales, de extenderse. Por poner tan sólo 
un ejemplo: desde 1978, la dinámica de la economía china obliga a reexaminar seriamente la posibilidad de una acumulación y un régimen de crecimiento en el cual la competencia sea la forma institucional dominante... y, sin embargo, esto no es en lo más mínimo la repetición de un episodio de industrialización equivalente que tuvo lugar en Europa en la época del capitalismo competitivo (Boyer, 2011a). A riesgo de simplificar y, por tanto, de caricaturizar, los poskeynesianos avanzan por medio de la teoría, y los regulacionistas por medio del análisis histórico y comparativo. Por lo pronto, ésta es la explicación de la relativa autonomía de sus respectivas trayectorias de investigación. ¿Podría ser ésta la fuente de complementariedad, en vista de que las dos comunidades aceptarían colaborar en un proyecto preciso y, por tanto, estarían obligadas a discutir acerca de sus resultados y perspectivas? Por ejemplo, podrían responder a la pregunta: “¿qué teoría (s) y formalizaciones puede haber después de la crisis de las subprimes?". Sería la oportunidad para los poskeynesianos de confrontar sus diferentes modelos con el conjunto de hechos fundamentales característicos de las tres décadas pasadas y, para los regulacionistas, de evaluar el núcleo de su teoría macroeconómica.

Sin embargo, se plantea una segunda pregunta metodológica a la cual los dos bandos dan respuestas diferentes: ¿es metodológicamente correcto explicar la economía con la economía y, por tanto, cerrar la disciplina sobre sí misma y considerar como exógenas la técnica, la demografía, las normas sociales y la política? La práctica de los poskeynesianos sugiere que tal concepción no genera algún problema; por lo contrario, permite oponerla a la economía estándar y construir una alternativa. En contraste, el enfoque de los regulacionistas, desde su origen, criticó tal idea, mostrando que de esta forma se estaba ignorando el aprendizaje de la historia económica, de la sociología, del derecho y del análisis político, los cuales deben dar información al economista para la elección de sus hipótesis más esenciales... al menos si éste pretende privilegiar la pertinencia, aunque fuera en detrimento de la elegancia y la parsimonia (Boyer y Saillard, 1995 y 2002). ¿Acaso se trata de un abismo infranqueable? Seguramente lo es, si seguimos a pie juntillas las líneas de investigación que, en la escala internacional, estructuran el campo profesional de los economistas. Pero tal vez no lo es, si regresamos a Keynes: ¿acaso no fue él el observador -y en ocasiones el actorde los principales cambios que siguieron a la primera Guerra Mundial? Hay una lectura histórica de la Teoría general, presente en su último capítulo: no sólo la construcción de Pigou es teóricamente incorrecta en su tratamiento de la moneda, del trabajo y de la adopción de la ley de Say, sino que además manifiesta un alejamiento creciente de aquello en lo que se convirtieron las estructuras del 
capitalismo bajo los efectos de la concentración, el peso de las finanzas en las decisiones de inversión y el cambio en las relaciones laborales bajo los efectos de la sindicalización (Boyer, 1985). Por tanto, es importante reexaminar las condiciones del capitalismo y tomarlas en cuenta para cualquier esfuerzo de teorización. Establecer un diagnóstico compartido sobre el tema podría resultar fructífero y no tan difícil, si leemos entre líneas la representación que tienen los poskeynesianos del capitalismo contemporáneo.

\section{Las grandes crisis: Innovaciones institucionales y no sólo una reafirmación de las políticas keynesianas}

Toda teoría macroeconómica tiene implicaciones relacionadas con los objetivos y las herramientas de la política económica. Es el caso en particular de los keynesianos y los poskeynesianos, cuyos análisis muestran cómo los mercados, dejados a su suerte, conducen al desempleo involuntario y/o a la inestabilidad financiera. La política económica entonces es decisiva: no siempre es una interferencia perjudicial para la eficacia económica, contrariamente a lo que afirma la nueva teoría clásica. Por su parte, los enfoques regulacionistas reconocen tal inestabilidad, pero ésta proviene del proceso de acumulación del capital tanto productivo como financiero. No es posible contenerla, al menos durante un tiempo, más que para ciertas arquitecturas institucionales que combinan formas específicas para la competencia, el tabulador salarial y el régimen monetario y financiero. Las relaciones Estado-economía forman parte de estas condiciones, pero su desempeño no es exclusivo. El alejamiento de los preceptos keynesianos se puede medir en cada una de las grandes etapas que se fueron sucediendo después de la crisis de la década de los treinta.

- La tradición keynesiana considera que la profundidad de la depresión estadounidense observada entre 1929 y 1932 se debe a errores manifiestos en la conducta de la política económica: tentativas desesperadas de reducir los déficit públicos y políticas monetarias demasiado restrictivas. Las investigaciones regulacionistas más bien destacan la contradicción inherente a un régimen de acumulación intensiva, basada en la producción masiva, sin un movimiento equivalente del consumo. A su vez, este desequilibrio estructural deriva de la incoherencia entre una revolución de las condiciones sociales y las técnicas de producción, por un lado, y un tabulador salarial que siguió siendo competitivo. En efecto, aun cuando 
los asalariados se convierten en mayoría, su consumo permanece acorde con el crecimiento anterior, moderado, de los ingresos en el mismo momento en que estalla la producción. Tal divergencia explosiva-que se manifiesta por un nivel muy elevado de las tasas de beneficio- al ser imposible de sostener, no hubiera podido compensarse por un incremento del gasto público... salvo si imaginamos, por ejemplo, un camino hacia una economía de guerra, como fue el caso de Alemania durante el Tercer Reich. Cualquiera que sea el caso, una reconfiguración institucional se imponía para que la economía de Estados Unidos recuperara un camino de crecimiento duradero.

- Lo anterior es lo que interviene a favor del new deal y de las reformas emprendidas al término de la segunda Guerra Mundial. El poder conferido a los asalariados para negociar acuerdos colectivos instituye una importante desvinculación del salario con respecto a la situación del "mercado del empleo", es decir, del desempleo. Esto garantiza una sincronización ex ante entre la extensión de las capacidades de producción y la formación de la demanda, generada por el consumo de los asalariados. A partir de que este motor del modelo de acumulación fordista se pone en marcha, las políticas monetarias y presupuestales vienen a limar las evoluciones macroeconómicas, acelerando el ritmo en caso de recesión y frenándolo cuando despunta la inflación. La adopción de los principios keynesianos por parte de todos los gobiernos -sin importar su orientación política- viene a coronar una arquitectura institucional nacida de un compromiso sociopolítico fundador. Dependiendo de los enfoques, esta configuración se conoce como economía mixta si insistimos en las relaciones privado/público (Shonfield, 1967), o de Estado social, si le damos preponderancia a la función determinante de la cobertura social (Billaudot, 2008), y, por supuesto, de Estado keynesiano, si pretendemos insistir en la función determinante de la política económica para estabilizar la economía. Para la corriente regulacionista, el conjunto de estas características fue lo que le dio coherencia al régimen de la posguerra: fue a la vez fordista, beveridiano o bismarkiano (según el tipo de cobertura social financiada por los impuestos o las cotizaciones sociales), y finalmente keynesiano en cuanto a la conducta de la política económica.

- Esta caracterización implica algunos análisis de la crisis iniciada en 2008, que no necesariamente convergen entre poskeynesianos y regulacionistas. 
Para estos últimos se abrió un periodo de recomposición del conjunto de formas institucionales, dado que los regímenes de acumulación derivados de las finanzas llegaron a su límite. El impasse surgido de esta crisis no se debe solamente al abandono de los principios keynesianos. Tres episodios se adjudican la relativización del impacto de las políticas económicas, entendidas en sentido estricto, frente a una gran crisis en el sentido del enfoque de la regulación. En la década de los ochenta, los gobiernos que habían perseverado en las políticas de relanzamiento, con miras a contener la crisis de los regímenes posteriores a la segunda Guerra Mundial, finalmente se vieron obligados a abandonarlas: el keynesianismo, en un país abierto a la competencia internacional y con un sistema productivo frágil, conduce al fracaso, tal como lo demuestra la experiencia francesa de 1981 a 1983. La misma lección se impone frente al fracaso de las tentativas, repetidas a lo largo de casi dos decenios, de las autoridades japonesas para reactivar la economía mediante el gasto público: sólo el dinamismo de las exportaciones evitó el colapso del crecimiento y el hecho de que un endeudamiento público acumulativo hipotecara la credibilidad del yen. El uso y el abuso del acelerador no compensaría las fragilidades del motor del crecimiento nipón. Sin embargo, el ejemplo más significativo es el estadounidense: después de septiembre de 2008, los estabilizadores automáticos y la reducción de la fiscalidad y la abundancia de liquidez seguramente evitaron, desde la primavera de 2009, una posible depresión; pero esta intervención masiva de los poderes públicos no permitió al sector privado retomar el camino de la inversión y del crecimiento: las ganancias nuevamente alcanzan niveles elevados, pero el dinamismo de la demanda se atrasa. Habremos reconocido eso que los teóricos de las Social Structures of Accumulation (SSA) denominan un ciclo no productivo... y los regulacionistas, una gran crisis. Ante un episodio de esta naturaleza, más vale ser adepto a los principios keynesianos que a los de la macroeconomía walrasiana, pero el comportamiento de la política monetaria y presupuestaria está lejos de ser un sustituto eficaz para una recomposición general de las formas institucionales.

Así, esta divergencia de análisis -y por consiguiente de consejo de política económica- nos regresa, en primer lugar, al asunto de la incorporación de las instituciones en la macroeconomía. Si los poskeynesianos pretenden proveer una 
teoría que trascienda las configuraciones institucionales (Pasinetti, 1981), el diálogo con la corriente regulacionista, a priori, es difícil. En segundo lugar, y sobre todo, ¿acaso podemos asimilar legítimamente las crisis de 1929 y de 2008 como un ciclo, simplemente más marcado que los observados en un modo estabilizado de regulación? Por lo contrario, para el enfoque en términos de endometabolismo, se trata de una discontinuidad que marca una bifurcación en el camino de la evolución. Ahora bien, son pocos los modelos poskeynesianos que manifiestan esta propiedad. ¿Acaso podemos concebir que se inicie un proyecto para producir formalizaciones de este tipo al interior mismo del paradigma keynesiano? Algunos trabajos, muy anteriores, que sugieren la existencia de comportamientos no lineales de la inversión y del ahorro, pueden servir de base a la investigación de bifurcaciones; es decir, pueden dar cuenta de la especificidad de las depresiones, en contraposición a las recesiones moderadas que operan en las inmediaciones de un camino (Kaldor, 1940).

\section{4. ¿Poder de persuasión o comprensión de los procesos políticos de formación de la política económica?}

¿Acaso el economista puede y debe ser normativo y valerse de la especificidad de estas investigaciones para convertirse en consejero del rey? Este punto ya fue abordado en la discusión de los problemas epistemológicos suscitados, dentro de la corriente regulacionista, por la introducción de lo político. De conformidad con un enfoque realista, es necesario cuestionarse acerca del proceso que conduce de la construcción de una teoría a sus eventuales efectos sociales. Por otra parte, regresa rápidamente la tentación favorita del economista teórico: su construcción es demasiado coherente como para no representar una parte importante del mundo económico. Sólo los prejuicios, la herencia de las teorías ya obsoletas desde hace mucho tiempo y la grandísima novedad de un descubrimiento, prohíben a los actores echar mano y tomar en cuenta esta construcción. Ésta ya era la posición que expresaba Keynes en las conclusiones de la Teoría general. Ahora bien, el avance de la sociología de las ciencias abre una perspectiva totalmente nueva: la naturaleza de la inserción de los economistas en la sociedad determina, en gran medida, la dirección de sus esfuerzos y el tipo de difusión de sus trabajos con los actores. Las configuraciones correspondientes evolucionan en un largo periodo, como lo muestra la trayectoria francesa de 1815 a 1950 (Le Van-Lemesle, 2004) y pueden diferir notoriamente en función de las sociedades, tal como lo 
explicita una comparación entre Estados Unidos, el Reino Unido y Francia desde 1890 (Fourcade, 2010).

A este tipo de programa de investigación es precisamente al que se adhirieron varios regulacionistas. Primero, al construir una topología general de lo social en la cual la moneda, el derecho y la intelectualidad son las tres mediaciones de base que pueden concretarse en diferentes configuraciones dotadas de cierta coherencia (Théret, 1999). Segundo, al mostrar a qué grado una misma política puede recibir múltiples y sucesivas justificaciones y que lo cognitivo -en este caso, la diversidad de representaciones de la economía- desemboca en una cuestión de poder, particularmente en materia de política económica (Lordon, 1997a). Por consiguiente, es necesario tomar en serio la estructuración del campo político, su grado de reacción a las demandas de los ciudadanos y de diversos grupos de interés, ya que éste puede ser el origen de crisis tanto políticas como económicas (Palombarini, 2001; Amable y Palombarini, 2005 y 2009). De manera recíproca, las grandes crisis no se superan mediante la puesta en marcha de un plan racional y coherente, sino mediante un proceso de reajuste de las relaciones de poder que atraviesan tanto lo económico como lo político. La crisis que dio inicio en 2008 no es la excepción (Boyer, 2011b).

¿Qué consecuencias se pueden obtener de esta confrontación entre dos estilos y dos programas de investigación?

\section{HACIA POSIBLES COOPERACIONES}

Si a partir de los desarrollos previos tenemos la impresión de que existe una compatibilidad, o incluso una complementariedad deseable entre ellos, podemos proponer algunos de los siguientes campos de trabajo:

\section{Tomar en serio la función de las instituciones en la coordinación entre actores, es decir, la macroeconomía}

A partir del momento en que se renuncia a la visión de los mercados autoinstituidos, y luego autorregulados, y que se toman en cuenta los desequilibrios impulsados por la acumulación y la innovación, resulta necesario cuestionarse acerca de los mecanismos susceptibles de reequilibrar estas inestabilidades recurrentes. Una larga tradición teórica, desde Commons y Veblen, responde que ésa es la función de las reglas del juego, las normas sociales, las organizaciones y las instituciones. Finalmente, esto fue lo que introdujo, en los análisis de inspiración 
marxista, la macroeconomía histórica e institucionalista del enfoque regulacionista (Boyer y Saillard, 1995). ¿La corriente poskeynesiana estaría dispuesta a examinar esta opción o prefiere, por comodidad, enfrentar a la macroeconomía estándar, al seguir fingiendo que las instituciones no desempeñan papel alguno o si acaso marginal, o pensando que pueden obtenerse muchos resultados genéricos, es decir, independientes del contexto histórico? Esto último sería una lástima, pues significa olvidar que las reglas del juego y las instituciones tienen una función de reducción de las inestabilidades, algunas de las cuales no son propensas a ser reabsorbidas exclusivamente por la política económica. De este modo se explican, por ejemplo, los comportamientos de la economía alemana: la naturaleza de las reglas de coordinación fuera del mercado es mucho más determinante en este contexto que la adhesión a los principios keynesianos, que parecen no haber sido nunca dominantes (Boyer, 2011d).

A un nivel más teórico, el tratamiento de las interacciones entre agentes es una etapa necesaria de cualquier transición de lo micro a lo macro, y viceversa. Por ejemplo, la formación de los salarios está tratada en la teoría estándar como keynesiana, por el asunto de la racionalidad de las previsiones de la inflación, tanto de su formación como de su incorporación, de donde derivan los posibles cambios en la forma de las relaciones de Phillips (Palley, 2011). Además, así podemos demostrar que, dependiendo del grado de coordinación respectiva de los empresarios y los asalariados, su forma cambia radicalmente (Bowles y Boyer, 1988). ¿Por qué no confrontar estos dos enfoques con miras a una investigación conjunta?

\section{Comprobar sistemáticamente el poder explicativo de las diversas generaciones de modelos teóricos y organizar así su selección}

El propósito no es reiterar la ilusión positivista de que la refutación permanente de las teorías debería orientarse hacia la detección del "verdadero modelo de la economía". Esto se excluye si adoptamos una epistemología realista crítica para la cual pueden coexistir representaciones inconmensurables de un mismo sistema económico. Por lo contrario, es importante retomar el criterio de pertinencia respecto del criterio de coherencia en la investigación en macroeconomía: la elegancia y la parsimonia no podrían justificar la persistencia de teorías y modelos incapaces de reproducir el más mínimo hecho estilizado y cuyo irrealismo en las hipótesis y las conclusiones es aún más patente frente a la crisis iniciada en 2008 (Krugman, 2009). 
Por tanto, es tarea de todo programa de investigación detectar aquellos caminos que llevan a un impasse y reportar sus esfuerzos en las avenidas, donde una primera exploración mostró una riqueza de enfoques. Sin embargo, no es posible mantener la ilusión de que este proceso bastará para disolver las diferencias de paradigma. Una amplia fracción de la trayectoria intelectual de la corriente regulacionista se explica de la siguiente manera: invalidación de la generalidad del régimen fordista, reevaluación drástica de la hipótesis de un retorno a una regulación competitiva, refutación de la visión que hace de la globalización el vector de la convergencia de los capitalismos o, más aún, el cuestionamiento acerca de la creencia en la eficiencia de los mercados financieros y de la viabilidad de unas finanzas sin ningún tipo de regulación.

¿Sería posible imaginar que la productiva corriente poskeynesiana procediera a una reevaluación del mismo tipo, con la finalidad de poder confrontar sus resultados con aquellos que, en el pasado, los regulacionistas intentaron obtener a partir de diferentes investigaciones y publicaciones colectivas?

\section{Enriquecer los mecanismos keynesianos para aprehender mejor la dinámica macroeconómica}

Si bien el principio de la demanda efectiva es central, éste no podría, por sí mismo, resumir el conjunto de los feedbacks (positivos y negativos) que rigen la dinámica de economías en las cuales los mercados financieros ocupan un lugar central. A este respecto, el encadenamiento de sucesos posteriores a la quiebra de Lehman Brothers muestra la fuerza de la espiral que vincula el exceso de endeudamiento, las ventas de pánico y la deflación en la línea del modelo de Irving Fisher (1933), más aún porque ésta repercute desde el mercado de los productos hasta el mercado de los activos financieros, y viceversa. Del mismo modo, los efectos de la riqueza, tanto inmobiliaria como financiera, conformaron la partición consumo/ahorro de los hogares, y más aún porque las restricciones al otorgamiento de créditos se habían relajado considerablemente. Asimismo, los efectos de la reverberación entre mercados inmobiliarios, de crédito y la bolsa deben ser tomados en cuenta, pues su conjunción puede ayudar a que la economía atraviese el umbral de la inestabilidad estructural (Boyer, Dehove, Plihon, 2004).

Se abre entonces un programa de investigación con miras a una formalización realista de los mercados financieros y de sus interacciones con la economía real (Chiarella et al., 2009). Sin embargo, no habría que desatender los mecanismos clásicos (Flaschel et al., 1997) y marxistas (Duménil y Lévy, 1993 y 
2002) que gobiernan la distribución de los ingresos y la acumulación del capital productivo. Aunque, sin lugar a dudas, esto significa replantearse, a la luz de la crisis actual, la cuestión de los análisis cruzados que nos brindan las corrientes marxistas y keynesianas, un tema ya explorado para la crisis de la década de los treinta (Baran y Sweezy, 1969) y, luego, para la crisis de la década de los setenta (Duménil, 1977). Tomando en cuenta los orígenes de los enfoques de la regulación, convergencia de una filiación marxista crítica, de la escuela histórica de los Anales y de las herramientas de la macroeconomía kaleckiana y keynesiana, una ramificación de este tipo no queda fuera del alcance.

\section{Asociar a cualquier modelo una dinámica lenta, susceptible de erosionar su estabilidad estructural}

En la misma medida en que Keynes se preocupaba por la formación de un equilibrio de corto plazo, cuya sucesión terminaba por definir una trayectoria ex post, los macroeconomistas contemporáneos adoptaron la doble hipótesis de los mercados walrasianos y de las expectativas racionales e impusieron que cualquier modelo debe exhibir un equilibrio de largo plazo dotado de estabilidad. Si además procedemos a la linealidad a lo largo de este camino, sólo los choques exógenos -tecnológicos, monetarios y financieros- pueden perturbar transitoriamente esta evolución regular. Fieles a esta práctica y a este credo, algunos economistas persisten y señalan: la crisis iniciada en 2008 no proviene más que de un choque exógeno y negativo de la productividad del sector inmobiliario estadounidense (Minford, 2009).

A su manera, algunos poskeynesianos son sensibles al hecho de que un modelo, para ser satisfactorio, debe tener propiedades (de largo plazo) asintóticas tales que exista un camino estable de largo plazo. Esta rigurosa metodología es bienvenida para los modelos llamados Stock-Flow-Consistent (SFC), ya que de este modo delimitan las importantes restricciones que pesan sobre los ajustes monetarios y financieros (Godley y Cripps, 1983; Godley y Lavoie, 2007). Sin embargo, si se restringen así los parámetros del modelo, por su construcción, ninguna crisis financiera puede intervenir. La propuesta derivada de los análisis en términos de endometabolismo sería la de completar esta primera etapa con otras dos. Primero, tomando en cuenta algunas no-linealidades, ¿acaso el modelo puede presentar varios caminos de evolución? Después, si esto sucede, ¿acaso se puede formular una hipótesis basada en la lenta evolución de algunos parámetros, la 
cual es susceptible de introducir una brutal discontinuidad de las variables macroeconómicas debido al vaivén entre un camino y otro?

La anterior sería una forma de introducir, en las teorizaciones poskeynesianas, la noción de gran crisis y la idea de que, en ciertas configuraciones, un cambio a priori marginal es susceptible de tener grandes consecuencias. Esto es especialmente pertinente cuando concierne a la génesis de las crisis financieras; en particular, las crisis bursátiles. En efecto, los modelos que formalizan las interacciones entre agentes heterogéneos, dentro de los mercados financieros, pueden reproducir sin dificultad una fase de aceleración que se propaga por mimetismo, seguida de un brutal colapso (Sornette, 2003). Así, una serie de transformaciones marginales puede desembocar en una bifurcación, un antídoto contra la práctica de la macroeconomía estándar, que sigue invocando choques excepcionales externos para rendir cuenta de las crisis.

\section{CONCLUSIÓN: LOS OBSTÁCULOS INSTITUCIONALES QUE SE DEBEN SUPERAR}

¡Menudo programa! ¿Habrá alguna posibilidad de llevarlo a cabo, al menos parcialmente? Una apreciación realista se impone, ya que ¿por qué habrían de ser posibles hoy en día las colaboraciones que, en el pasado, no fueron más que episódicas y no tuvieron un impacto significativo en ninguno de los dos programas de investigación?

- En primer lugar, en el plano intelectual y en el plano más fundamental, la teoría marxista -de donde derivan los enfoques de la regulación y el keynesianismo, al cual a su vez se encomiendan los poskeynesianos- no puede integrarse fácilmente en una síntesis, pues los seguidores de uno y de otro enfoque van a polemizar y a argumentar que el suyo es claramente superior y/o puede englobar al otro. La intención no es lograr una gran unificación de dos heterodoxias mayores, sino incorporar elementos y mecanismos probadamente pertinentes en una base común de modelos macroeconómicos que respondan a la situación actual de los diversos capitalismos. Así como la macroeconomía walrasiana contemporánea tenía un modelo de base y los economistas evolucionistas encontraron los medios para construir una plataforma común que permitiera comparar diversas generaciones de modelos multiagente, ¿por qué no ponerse de acuerdo para armar un modelo, ciertamente simplificado, pero que 
capture lo esencial de las hipótesis e intuiciones poskeynesianas y regulacionistas? Un esfuerzo equivalente se emprendió para medir las respectivas contribuciones de los mecanismos schumpeterianos y keynesianos a la explicación de la estabilidad y la intensidad del crecimiento (Dosi, 2008).

- Por otra parte, no debemos olvidar la creciente influencia de las incitaciones propias del mundo académico sobre las elecciones de los investigadores economistas. Los mecanismos vinculados a las condiciones de acceso a la profesión, a las facilidades de promoción, a la jerarquía de las publicaciones y a la capacidad de obtener financiamiento son los que seguramente explican, en gran medida, que jóvenes y talentosos economistas inscriban sus trabajos en el marco de modelos tipo DSGE, que hasta la fecha creen infundados. Frente a este poderoso atractivo, la tentación de reagruparse es fuerte para los disidentes (los heterodoxos), pero si siguen fraccionados en pequeñas comunidades en las que cada grupo sólo venera a sus fundadores: Marx, Keynes, Schumpeter, Polanyi, Commons..., de manera a veces subrepticia, se introduce un segundo sesgo: cada heterodoxia pretende reemplazar a la ortodoxia. A veces, una heterodoxia logra que la ortodoxia adopte alguna de sus intuiciones, sin que nunca se le reconozca como tal. La historia de la incorporación de los rendimientos crecientes en la teoría del crecimiento endógeno es ilustrativa de este quid pro quo, que es doloroso para los heterodoxos.

Entonces, ¿por qué los heterodoxos no podrían construir un espacio de discusión en el cual pudieran periódicamente confrontar sus avances y trataran de construir un campo base común, a partir del cual cobrarían sentido las elecciones estratégicas de cada programa de investigación?

El fracaso abismal de la macroeconomía ortodoxa y el largo y doloroso trayecto (muddling throng, dirían los colegas anglosajones) que detona la crisis iniciada en 2008 permiten augurar un periodo de renovación de las teorías económicas, equivalente al que aconteció a partir de la década de los treinta. Sin embargo, este periodo será aún más difícil debido a la manera en que se han hecho complejas las interacciones e interdependencias que le dan forma al devenir de las economías capitalistas. 


\section{REFERENCIAS BIBLIOGRÁFICAS}

Aglietta, Michel (1976), Régulation et crises du capitalisme, París, Calmann-Lévy, 2a. edición [1982].

_ (1998), "Le capitalisme de demain”, Note de la fondation Saint-Simon, noviembre.

— y André Orléan (dir.) (1998), La monnaie souveraine, París, Odile Jacob.

— y André Orléan (2002), La monnaie entre violence et confiance, París, Odile Jacob.

— y Antoine Rebérioux (2004), Les dérives du capitalisme financier, París, Albin Michel.

Amable, Bruno, y Stefano Palombarini (2005), L'économie politique n'est pas une science morale, París, Raison d'Agir.

y- (2009), “A Neorealist Approach to Institutional Change", Socio-Economic Review, 7 (1).

— Donatella Gatti, y J. Schumacher (2006), "Welfare-State Retrenchment, The Partisan Effect Revisited", Oxford Review of Economic Policy, 22 (3).

_ L Lilas Demmou y Donatella Gatti (2007), "Employment Performance and Institutions: New Answers to an Old Question", IZA Discussion Paper, núm. 2731.

Aoki, Masahiko (2002), Toward a Comparative Institutional Analysis, Cambridge Ma. MIT Press.

Asensio, Angel, y Dany Lang (2010), "La rupture méthodologique de Keynes: une approche pos-keynésienne", La Lettre du CEPN, marzo.

— , Sébastien Charles, Edwin le Héron, y Dany Lang (2011), "Les développements Récents de la macroéconomie pos-keynésienne”, Revue de la régulation, núm. 10.

Balasko, Yves, y Robert Boyer (1983), "Employment, Increasing Returns and Technical Progress", Mimeograph CEPREMAP, febrero, $38 \mathrm{pp}$.

Baran, Paul A., Paul M. Sweezy (1969), Le capitalisme monopoliste, Maspéro-La Découverte, París; (1966) Monopoly Capital, Nueva York, Monthly Review Press.

Benassy, Jean-Pascal, Robert Boyer, Rosa-Maria Gelpi, Alain Lipietz, Jacques Mistral, José Muñoz, y Carlos Ominami (1978), “Approches de l'inflation l'exemple français", Recherches Économiques et Sociales (CORDES), La Documentation Française núm. 12, octubre 1978, pp. 7-59.

Bertrand, Hugues (1983), “Accumulation, régulation, crise: un modèle sectionnel théorique et appliqué", Revue Economique, Vol. 34, núm. 2, marzo, pp. 305-343.

Bhaduri A., y Steven Marglin (1990), "Unemployment and the Real Wage: The Economic Basis for Contesting Political Ideologies", Cambridge Journal of Economics, Vol. 14, núm. 4. 
Billaudot, Bernard (1996), L'Ordre Économique de la Société Moderne, París, L’Harmattan.

(2001), Régulation et croissance. Une macroéconomie historique et institutionnelle, París, L'Harmattan.

- (2008), "Une Théorie de l'Etat Social”, Revue de la régulation, núm. 2, enero.

Bowles, Samuel, y Robert Boyer (1988), "Labor Discipline and Aggregate Demand: A Macroeconomic Model”, American Economic Review, Vol. 78, núm. 2, mayo, pp. 395-400.

Boyer, Robert (1985), "Formes d'organisation implicites à la Théorie Générale. Une interprétation de l'essor puis de la crise des politiques économiques keynésiennes”, en A. Barrere (Ed.), Keynes aujourd'hui: Théorie et politiques, París, Éditions Economica, pp. 541-555.

_ (1988a), "Formalizing Growth Regimes Within a Regulation Approach. A Method for Assessing the Economic Consequences of Technological Change", en G. Dosi, Ch. Freeman, G. Silverberg, y L. Soete (comps.), Technical Change and Economic Theory: The Global Process of Development (2a. parte), Londres, Frances Pinter, pp. 608-630.

(1988b), "Technical Change and the Theory of 'Régulation"”, en G. Dosi, Ch. Freeman, G. Silverberg y L. Soete (comps.), Technical Change and Economic Theory: The Global Process of Development (1a. parte), Londres, Frances Pinter, pp. 67-94.

(1998 c), "De la 'Théorie Générale' à la nouvelle économie classique: Une réflexion sur la nouveauté en macroéconomie", Cahiers d'Economie Politique, núm. 33, L'Harmattan, pp. 7-56.

(2000), "Is a Finance-Led Growth Regime a Viable Alternative to Fordism? A Preliminary Analysis", Economy and Society, Vol. 29, núm. 1, febrero, páginas 111-145.

- (2010), "Taking Finance Seriously. Macroeconomics After the Crisis", presentado en la conferencia "Toward an Alternative Macroeconomic Analysis of Microfoundations, Finance-Real Economy Dynamics and Crises", organizada por INET, SIME and LEM, Budapest, 6-8 de septiembre, mimeo.

(2011a), "The Chinese Growth Regime and the World Economy", en Robert Boyer, Hiroyasu Uemura y Akinori Isogai (eds.), Diversity and transformations of Asian Capitalisms, Londres, Routledge, de próxima aparición.

(2011b), "Sortir de la finance", París, Economica.

(2011c), “Are There Laws of Motion of Capitalism?", Socio-Economic Review, Vol. 9, núm. 1, pp. 59-81. 
Boyer, Robert (2011d), "Succès et résilience de l'industrie allemande. Quelles leçons pour la France", Les Cahiers du Lasaire, núm. 42, París, abril.

y Jacques Mistral (1978), Accumulation, Inflation, Crises, Presses Universitaires de France, París, nueva edición (1982).

_ y Pascal Petit (1989), "Kaldor's Growth Theories: Past, Present and Prospects for the Future”, en W. Semmler y E. Nell (comps.), Nicholas Kaldor and Mainstream Economic, MacMillan, pp. 485-517.

— y Yves Saillard (1995), La Théorie de la Régulation, l'Etat des savoirs, París, La Découverte, nueva edición actualizada (2002).

_ Mario Dehove, y Dominique Plihon (2004), "Les crises financières: Analyse et proposition", Rapport du Conseil d'Analyse Economique, París, La Documentation Française.

Charpe Matthieu (2009), "Dette des ménages et instabilité financière”, Revue de la Régulation, núm. 5, 1er. semestre, http://regulation.revues.org/index7464.htlm.

Chiarella C., Peter Flaschel, y R. Franke (2009), Financial Markets and the Macroeconomy. A Keynesian Perspective, Londres, Routledge.

Dosi, Giovanni (2008), "Schumpeter Meeting Keynes: A Policy Friendly Model of Endogenous Growth and Business Cycles", LEM paper Series, Santa Ana School of Economics.

Duménil, Gérard (1977), "Marx et Keynes face à la crise”, París, Economica.

— y Dominique Lévy (1993), The Economies of the Profit Rate Competition, Crises, and Historical Tendancies in Capitalism, Edward Elgar, Chentelham.

— y - (2002), "Économie marxiste du capitalisme”, Repères, París, La Découverte, núm. 349.

Escuela de las convenciones (1989), Revue Economique, número especial.

Fisher, Irwing (1933), "Debt-Deflation Theory of Great Depressions", Econometrica, W. Semmler y E. Nell (comps.), Vol. 1, núm. 4, pp. 337-357.

Flaschel, Peter, Reiner Franke, y Willi Semmler (1997), Dynamic Macroeconomics, Instability, Fluctuations, and Growth in Monetary Economics, Cambridge, The MIT Press.

Fourcade, Marion (2010), Economists and Societies. Discipline and Profession in the United States, Great Britain and Finance, Princeton, Princeton University Press.

Godley, Wynne, y Francis Cripps (1983), Macroeconomics, Cambridge, Oxford University Press.

— y Marc Lavoie (2007), Monetary Economics: An Initegrated Approach to Credit, Money, Incomen Production and Wealth, Londres, Palgrave-MacMillan. 
Goodwin, Richard (1967), “A Growth Cycle”, en C.H. Feinstein (comp.), Socialism, Capitalism and Economic Growth, Cambridge, Cambridge University Press.

Harcourt, G.C. (1987), "Pos-Keynesian Economics”, en John Eatwell, Murray Milgate y Peter Newman (comps.), A Dictionary of Economics, Vol. 3, New Palgrave, pp. 924-928.

Kaldor, Nicholas (1940), "A Model of the Trade Cycle”, Economic Journal, Vol. 50, núm. 197, pp. 78-92.

— (1985), Economics without Equilibrium, MacMillan, Nueva York, Armonk.

- (1987), "Economie et Instabilité”, texto presentado por Robert Boyer, De Largentaye Bertrand, Petit Pascal, Schmeder Geneviève, Schrameck-De Largentaye Hélène, París, Economica.

Keynes, John-Maynard (1936), The General Theory of Employment, Interest and Money, Cambridge, Cambridge University Press,.

Krugman, Paul (2009), "Why did Economists get it so Wrong?”, The New York Times, 2 de septiembre.

Kuhn, Thomas (1962), La Sructure des Révolutions Scientifiques, traducción al francés (1983), Champs, París, Flammarion.

Lawson, Tony (2003), Reorienting Economics, Londres, Routledge.

Le Van-Lemesle, Lucette (2004), Le juste et le riche. L'enseignement de l'économie politique, 1815-1950, París, Comité pour l'histoire économique et financière de la France.

Lordon, Frédéric (1997a), Les quadratures de la politique économique, París, Albin Michel.

— (1997 b), "Endogenous Structural Change and Crisis in a Multiple Time-Scales Growth Model”, Journal of Evolutionary Economics, Vol. 7, núm. 1.

Lucas, Robert E. (1983), Studies in Business Cycle Theory, Cambridge Ma., The MIT Press.

Minford, Patrick (2009), “The Banking Crisis: A Rational Interpretation”, Conferencia Económica CESIFO "What's wrong with modern macroeconomies”, Munich, 6 y 7 de noviembre.

Minsky, Hyman (1986), Stabilizing an Unstable Economy, Mc Graw-Hill.

Nishi, Hiroshi (2011a), "Formalizing Debt-Led and Debt-Bburdened Growth Regimes with Endogenous Macrodynamics of Minskian Financial Structure: A LongRun Analysis", Documento de Trabajo núm. E-10-016, Kyoto University, Graduate School of Economics, marzo.

- (2011b), “The Consequences of Internationalization of Trade and Financial Transactions on Growth: Combining an Institutional Hierarchy Hypothesis with 
a Keynes-Minsky Approach”, en Robert Boyer, Hiroyasu Uemura y Akinori Isogai (comps.), Diversity and transformations of Asian Capitalisms, Londres, Routledge, de próxima publicación.

Nishi, Hiroshi (2011c), "A VAR Analysis for the Growth Regime and Demand Formation Patterns of the Japanese Economy", Revue de la Régulation, de próxima publicación.

North, Douglass C. (1990), Institutions, Institutional Change and Economic performance, Cambridge, Cambridge University Press.

Orléan, André (1990), "Le rôle des influences interpersonneles dans la détermination des cours boursiers", Revue Economique, núm. 41, pp. 839-868.

, André (1998), Le pouvoir de la finance, París, Odile Jacob Éditions.

Palley, Thomas (2011), "The Economics of Phillips Curve: Formation of Inflation Expectations Versus Incorporation of Inflation Expectations", The American Foundation, Washington, marzo.

Palombarini, Stefano (1999), "Vers une théorie régulationniste de la politique économique”, L’Année de la Régulation, Vol. 3, pp. 97-124.

(2001), La rupture du compromis social italien, París, CNRS Ediciones.

Pasinetti, Luigi (1981), Structural Change and Economic Growth. A Theoretical Essay on the Dynamics of the Wealth of Nations, Cambridge, Cambridge University Press.

Petit, Pascal (1998), "Formes structurelles et régime de croissance de l'après fordisme", L’Année de la Régulation, Vol. 2, pp. 169-196.

Robinson, Joan (1973), "Michael Kalecki”, Collected Economic Papers, Vol. 4, Oxford, Basil Blackwell, pp. 87-91.

(1974), "History Versus Equilibrium", Thames Papers in Political Economy. Reimpreso en Joan Robinson (1979), Collected Economic Papers, Vol. V, Oxford, Basil y Blackwell.

Setterfield, Mark (2007), “An Essay on Horizontalism, Structuralism and Historical Time", abril (no publicado) http://www.trincoll.edu/ setterfi.

(2011), "Anticipations of the Crisis: On the Similarities Between Pos-Keynesian Economies and Regulation Theory", Revue de la Regulation, de próxima publicación.

Shackle, Georges (1974), Keynesian Kaleidies, Edinburgo, Edinburg University Press.

Shonfield, Andrew (1967), Le capitalisme d'aujourd'hui. L'Etat et l'entreprise, París, Gallimard.

Sornette, Didier (2003), Why Stock Markets Crash? Critical Events in Complex Financial Systems, Princeton, N.J., Princeton University Press. 
Taylor, Lance, y S. O’Connell (1985), “A Minsky Crisis”, Quarterly Journal of Economics, Vol. 100, pp. 871-886.

Théret, Bruno (1999), "L'efficacité de la politique économique: de l'auto-poïese des systèmes sociaux à la topologie du social”, L'Année de la Régulation, núm. 3.

Thirlwall, Anthony, y John McCombie (1004), Economic Growth and the Balance of Payment Constraint, Nueva York, MacMillan. 